\title{
Case Report Opportunistic Infections in Patients with HTLV-1 Infection
}

\author{
Toshiki Tanaka, ${ }^{1}$ Toshio Sekioka, ${ }^{1}$ Masakatsu Usui, ${ }^{1}$ and Shinsaku Imashuku ${ }^{2}$ \\ ${ }^{1}$ Department of Internal Medicine, Uji-Tokushukai Medical Center, Uji 611-0042, Japan \\ ${ }^{2}$ Department of Laboratory Medicine, Uji-Tokushukai Medical Center, Uji 611-0042, Japan \\ Correspondence should be addressed to Shinsaku Imashuku; shinim95@mbox.kyoto-inet.or.jp
}

Received 13 June 2015; Revised 22 September 2015; Accepted 27 September 2015

Academic Editor: Eduardo Arellano-Rodrigo

Copyright (C) 2015 Toshiki Tanaka et al. This is an open access article distributed under the Creative Commons Attribution License, which permits unrestricted use, distribution, and reproduction in any medium, provided the original work is properly cited.

As an acquired immunodeficiency, human immunodeficiency virus (HIV) infection is primarily responsible for opportunistic infections in infected patients. However, opportunistic infections also occur in individuals with human T cell lymphotrophic virus type 1 (HTLV-1) infection. Here, we report opportunistic infections in two Japanese HTLV-1-seropositive patients. The first patient was a 67-year-old male, who had cytomegalovirus infection associated with esophagogastritis and terminal ileitis. The patient was HTLV-1-positive and was diagnosed with smoldering adult T cell leukemia (ATL). High levels of serum soluble IL-2 receptor (sIL$2 \mathrm{R} ; 4,304 \mathrm{U} / \mathrm{mL})$ and an increased percentage of CD4+CD25+ T cells $(75.5 \%)$ in peripheral blood were also detected. The second patient was a 78-year-old female, a known asymptomatic HTLV-1 carrier, who presented with persistent herpes zoster, followed by Pneumocystis jirovecii pneumonia. Disease progression of smoldering ATL along opportunistic infections was observed with very high levels of serum sIL-2R (14,058 U/mL) and an increased percentage of CD4+CD25+ T cells (87.2\%) in peripheral blood. In patients with suspected opportunistic infections, both HTLV-1 and HIV should be considered. In HTLV-1-positive patients, an increase in the CD4+CD25+ T cell subset may have its value as a prognostic marker.

\section{Introduction}

Human T cell leukemia virus type 1 (HTLV-1) infection is associated with asymptomatic HTLV-1 carriers and with the development of inflammatory HTLV-1-associated myelopathy/tropical spastic paraparesis (HAM/TSP) or adult T cell leukemia (ATL). Furthermore, HTLV-1 is associated with the development of opportunistic infections [1-4]. The risk of asymptomatic HTLV-1 carriers developing ATL is between $1 \%$ and $4 \%$ [2], although the factors promoting evolution from the healthy carrier state to symptomatic ATL are not well known. The incidence of opportunistic infections is higher in HTLV-1-infected individuals [3, 4]. As an acquired immunodeficiency, human immunodeficiency virus (HIV) infection is primarily responsible for opportunistic infections in affected patients. Although HTLV-1infected individuals are not as globally widespread as HIVinfected individuals, a high prevalence of HTLV-1 infection is observed in several countries, including Japan. In such countries, the physician should consider the patients current HTLV-1 infection status when opportunistic infections are suspected. It is believed that such opportunistic infections in HTLV-1-positive patients are not caused by the virus itself, but by alterations in the host's immune functions [1] In particular, retroviral infection of CD4+CD25+ T cells plays a major role in the pathogenesis of HTLV-1-related immunocompromised status [5-7]. Opportunistic infections in HTLV-1-infected individuals may cause multiple organ dysfunctions due to a mixture of cells responding to infection and infiltration by HTLV-1-infected cells [8]. Management of HTLV-1-associated opportunistic infections is difficult due to the lack of effective antiretroviral agents; thus, patients often have a dismal outcome. Here, we report two HTLV-1positive elderly patients in Japan, both of whom developed opportunistic infections. In one patient, initial symptoms associated with cytomegalovirus (CMV) gastroenteritis were observed, followed by confirmation of HTLV-1-positive status. The second patient was an identified HTLV-1 carrier who developed persistent herpes zoster and Pneumocystis jirovecii pneumonia (PCP). Both patients showed significant increases in the $\mathrm{CD} 4+\mathrm{CD} 25+\mathrm{T}$ cell subpopulation in peripheral blood in addition to opportunistic infections. 


\section{Case Report}

2.1. Case 1. In November 2014, a 67-year-old male (height, $163 \mathrm{~cm}$; weight, $44 \mathrm{~kg}$ ) presented with epigastralgia, anorexia, and excessive weight loss (10 kg per month). Endoscopic studies revealed multiple small ulcers extending from the cardiac to the pyloric region and an irregular shaped ulcer in the angular region of the stomach; however, a biopsy was not performed and the patient was treated with a histamine H2-receptor antagonist. Two months later, the patient presented at our clinic with a high fever, epigastralgia, diarrhea, and continuous anorexia. On admission, the patient was neither anemic nor icteric. No lymphadenopathy was noted. The blood test results are summarized in Table 1. A second endoscopy of the upper gastrointestinal tract revealed several ulcers at the esophagogastric junction of the lower esophagus. The gastric mucosa was edematous and reddish, and multiple ulcers were found in the corpus, angular region and in the greater curvature of the stomach. These results indicated an increase in both the number and size of the ulcers. Biopsies from these lesions showed inflammatory cell infiltrates associated with typical CMV intranuclear inclusion bodies, suggesting the presence of esophagogastric CMV infection (Figures 1(a) and 1(b)). We found it interesting that the patient was negative for CMV-IgM but was positive for CMV antigenemia. Colonoscopy identified two small ulcers in the terminal ileum and a large ulcer $(3 \mathrm{~cm})$ in the ileocecal valve. Histopathology of the biopsied tissues revealed CMV infection in the ileum and cecum (data not shown). Although the patient was initially suspected of having Behçet's disease, he was screened for immunodeficiency due to the opportunistic CMV gastroenteritis. The results revealed that the patient was HTLV-1-positive, with a high titer of antiHTLV-1 antibodies (1:1024). He was HIV-negative. A blood smear was carefully reexamined and abnormal lymphocytes with bizarre, convoluted nuclei were identified, although these were not the flower cells typically observed in cases of HTLV-1 infection (Figure 2(a)) [9]. An extremely high CD4+CD25+ T cell count in peripheral blood was identified by flow cytometry (Table 2). The patient was finally diagnosed with smoldering ATL. Initial treatment for Behçet's disease (mesalazine, $1.0 \mathrm{~g}, 3$ times per day) and infliximab (one $300 \mathrm{mg}$ infusion) was changed to ganciclovir $(250 \mathrm{mg}$, twice per day for 14 days) to treat CMV gastroenteritis, which significantly improved CMV antigenemia. However, high fever continued to be unresponsive to prednisolone (maximum $30 \mathrm{mg} /$ day) and intravenous immunoglobulin ( $5 \mathrm{~g} /$ day for 5 days). The patient was transferred to a university hospital for further care.

2.2. Case 2. A 78-year-old female (height, $142 \mathrm{~cm}$; weight, $41.8 \mathrm{~kg}$ ) had tested positive for HTLV-1 with a high titer of anti-HTLV-1 antibodies of 1: 4,096 four years earlier. During the next 4 years, the patient remained asymptomatic for HTLV-1 infection and did not undergo any specific treatment. In December 2014, the patient was hospitalized with herpes zoster in the left flank region. Laboratory data from 2010 and 2014 are shown in Table 1. The herpes zoster infection resolved following an acyclovir infusion (250 mg, twice per
TABLE 1: Laboratory data of two cases.

\begin{tabular}{|c|c|c|c|}
\hline \multirow[b]{2}{*}{ Year } & \multirow{2}{*}{$\begin{array}{c}\text { Case } 1 \\
2015\end{array}$} & \multicolumn{2}{|c|}{ Case 2} \\
\hline & & 2010 & 2014 \\
\hline $\begin{array}{l}\text { C-reactive protein } \\
(\mathrm{mg} / \mathrm{dL})\end{array}$ & 5.00 & 0.17 & 5.07 \\
\hline $\mathrm{WBC}(/ \mu \mathrm{L})$ & 15400 & 4700 & 2200 \\
\hline $\mathrm{Hb}(\mathrm{g} / \mathrm{dL})$ & 13.7 & 13.4 & 8.6 \\
\hline $\operatorname{PLTs}(/ \mu \mathrm{L})$ & $604 \mathrm{~K}$ & $212 \mathrm{~K}$ & $149 \mathrm{~K}$ \\
\hline AST (U/mL) & 20 & 23 & 33 \\
\hline $\operatorname{ALT}(\mathrm{U} / \mathrm{mL})$ & 28 & 19 & 35 \\
\hline $\mathrm{LDH}(122-228) \mathrm{U} / \mathrm{mL}$ & 155 & 185 & 456 \\
\hline Total protein $(\mathrm{g} / \mathrm{dL})$ & 5.9 & 7.8 & 4.8 \\
\hline Albumin (g/dL) & 2.6 & 4.5 & 2.7 \\
\hline BUN (mg/dL) & 13.3 & 7.4 & 10.5 \\
\hline Creatinine (mg/dL) & 1.01 & 0.68 & 0.67 \\
\hline $\operatorname{IgG}(\mathrm{mg} / \mathrm{dL})$ & 1001 & NT & NT \\
\hline $\operatorname{IgA}(\mathrm{mg} / \mathrm{dL})$ & 249 & NT & NT \\
\hline $\operatorname{IgM}(\mathrm{mg} / \mathrm{dL})$ & 76 & NT & NT \\
\hline $\mathrm{A} / \mathrm{G}$ ratio & NT & NT & 1.58 \\
\hline $\mathrm{Ca}(8.7-10.3) \mathrm{mg} / \mathrm{dL}$ & 8.7 & 9.4 & 8.4 \\
\hline sIL-2R (122-496) U/mL & 4,304 & 293 & 14,058 \\
\hline HTLV-1 Ab $(\mathrm{PA}<\times 16)$ & $\times 1,024$ & $\times 4,096$ & NT \\
\hline HIV-Ab & Negative & Negative & Negative \\
\hline HBV-Ag & Negative & Negative & Negative \\
\hline HBV-Ab & Positive & Positive & Positive \\
\hline $\mathrm{HCV}-\mathrm{Ab}$ & Negative & Negative & Negative \\
\hline CMV-IgM & Negative & Negative & Negative \\
\hline $\begin{array}{l}\text { CMV antigenemia } \\
(/ 50 \times 10 e 3 \mathrm{WBC})\end{array}$ & $\begin{array}{l}\text { Positive } \\
(89,91)\end{array}$ & $\begin{array}{l}\text { Negative } \\
(0)\end{array}$ & NT \\
\hline$\beta$-D-glucan $(0-20) \mathrm{pg} / \mathrm{mL}$ & 13.0 & 3.9 & 1,215 \\
\hline $\begin{array}{l}\text { Pj-PCR in BAL } \\
(<4 \times 10 e 1 / \mu \mathrm{g} \text { DNA })\end{array}$ & NT & NT & $9 \times 10 e 5$ \\
\hline
\end{tabular}

Ag: antigen, Ab: antibody, PA: particle agglutination, NT: not tested, Pj: Pneumocystis jirovecii, and BAL: bronchoalveolar lavage.

day for 5 days) but reappeared in the left encephalotrigeminal region and spread to the right chest and buttocks over a 3-month period. The patient showed bizarre-looking lymphocytes in the peripheral blood smear (Figure 2(b)). In January 2015, the patient also developed PCP, which was diagnosed on the basis of imaging studies (Figures 1(c) and $1(\mathrm{~d}))$ and the detection of Pneumocystis jirovecii $(9 \times$ $10^{5} / \mu \mathrm{g}$ DNA) in bronchoalveolar lavage fluid by quantitative polymerase chain reaction. She also had elevated levels of serum $\beta$-D-glucan $(>1,000 \mathrm{pg} / \mathrm{mL})$ (Table 1$)$. The pneumonia resolved following the oral administration of trimethoprimsulfamethoxazole (TMP-SMX, three tablets, three times per day for 2 weeks). However, in spite of the coadministration of MEPM, VCM, and MCFG, the fever persisted. The patient also had a mass in the right hepatic lobe and subcutaneous masses in the back and perineum; these were suspected to be noninfectious ATL-associated localized lymphomatous lesions [10]. The extremely high levels of serum soluble 

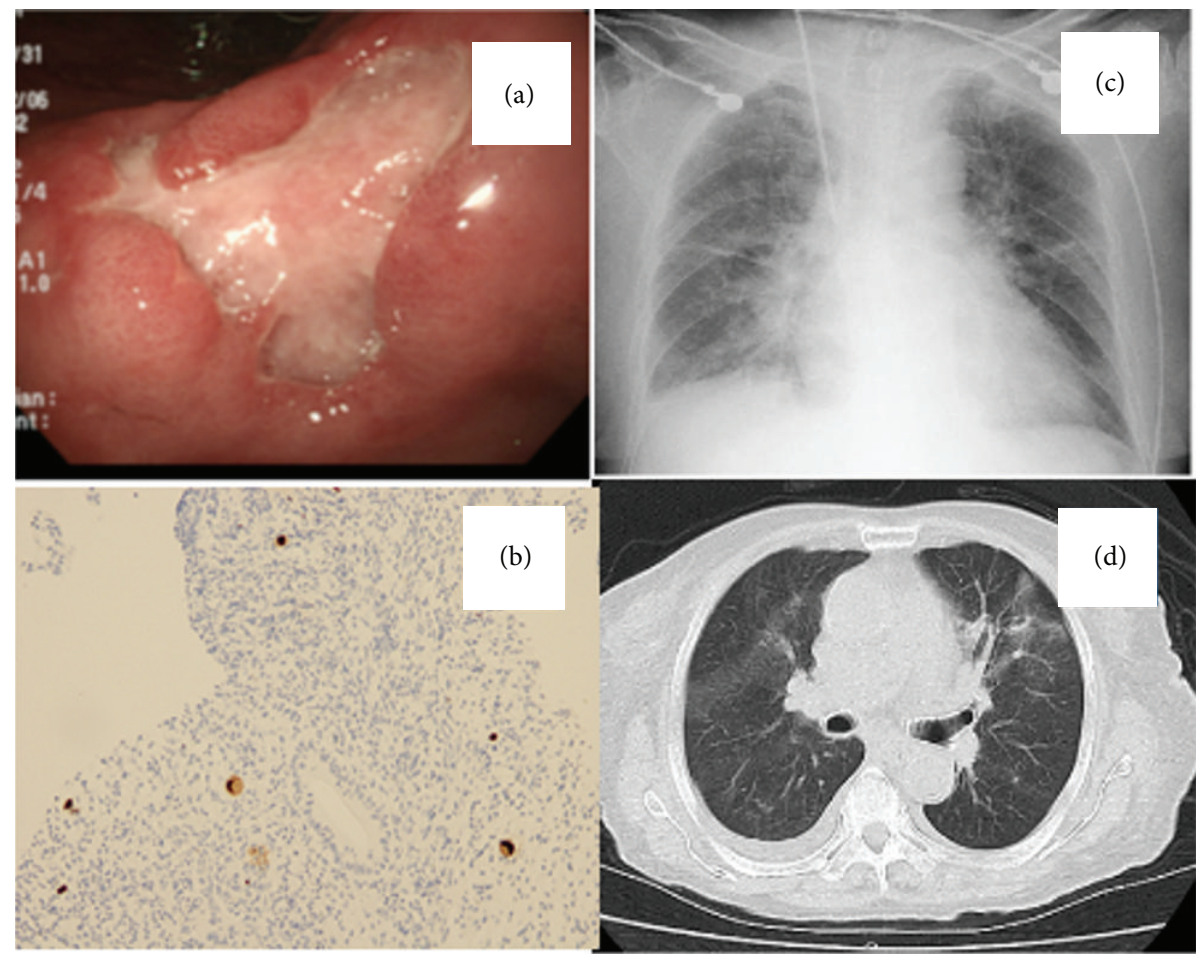

FIgURE 1: The opportunistic infections in the two HTLV-1-positive patients. (a) Gastric ulcers. (b) Positive staining of cytomegalovirus in a stomach biopsy (original magnification, $\times 400$ ), from case 1 . (c) Chest X-ray and (d) chest computed tomography images of the lungs showing fine nodular shadows and ground glass opacity, from case 2 .

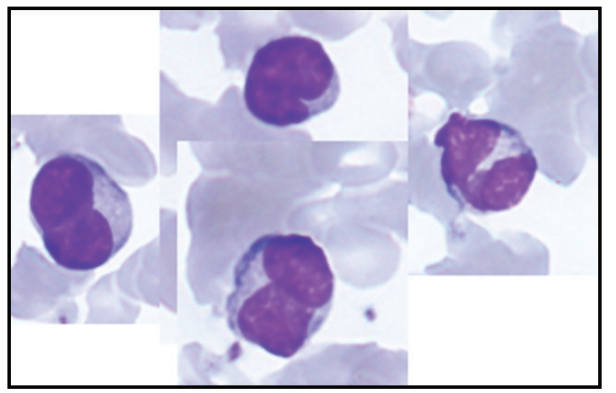

(a)

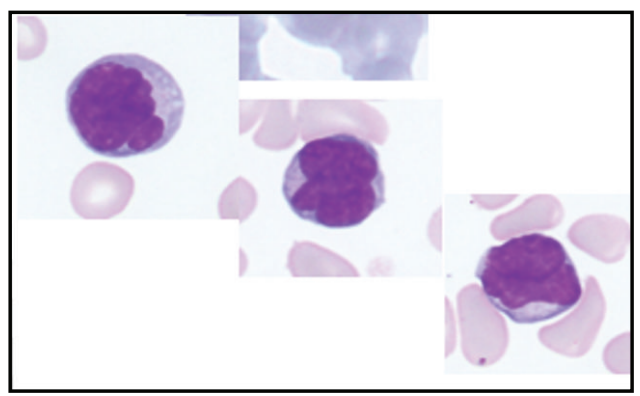

(b)

FIGURE 2: Lymphocytes with atypical convoluted nuclei: (a) in case 1 and (b) in case 2 (May-Grünwald-Giemsa stain; original magnification, $\times 1000)$.

interleukin-2 receptor (sIL-2R, 14,058 U/mL) and an increase in the percentage of CD4+CD25+ T cells (87.2\%) (Table 2) led us to believe that her HTLV-1 infection had progressed from carrier status to smoldering ATL. The patient was hospitalized for 4 months during which time her condition rapidly deteriorated and she died.

\section{Discussion}

Although HTLV-1 carriers do not necessarily develop opportunistic infections [9], Tashiro et al. [11] summarized HTLV-1related opportunistic infections occurring in 5 carriers and in 6 smoldering ATL cases. In patients with smoldering ATL, it is emphasized that close observation with careful monitoring for opportunistic infections is recommended [12]. In our case 1 , an initial diagnosis of CMV gastroenteritis was made, followed by the demonstration of HTLV-1 positivity. However, case 2 was a known HTLV-1 carrier and developed recurrent and intractable herpes zoster and PCP. We did not observe any neurological signs suggestive of HAM/TSP in either of our cases. Upon diagnosis of opportunistic infections, the patients were no longer HTLV-1 healthy carriers; they were in a progressive stage of smoldering ATL. The 3 cases described by Tashiro et al. [11] all developed overt ATL 14-16 months after the onset of opportunistic infections. D'Incan and colleagues [2] also proposed that opportunistic infections, 
TABLE 2: Flow cytometric data of peripheral blood mononuclear cells.

\begin{tabular}{lcc}
\hline & Case 1 & Case 2 \\
& $(\%)$ & $(\%)$ \\
\hline CD2 & 92.2 & 99.2 \\
CD3 & 81.0 & 91.5 \\
CD4 & 83.8 & 87.1 \\
CD5 & 90.3 & 95.5 \\
CD7 & 34.8 & 14.9 \\
CD8 & 6.7 & 7.6 \\
CD4/CD8* & $12.5^{*}$ & $11.5^{*}$ \\
CD10 & 0.2 & 0.2 \\
CD19 & 7.0 & 0.4 \\
CD20 & 7.0 & 0.5 \\
CD23 & 4.0 & 0.7 \\
Kappa & 2.0 & 0.4 \\
Lambda & 1.7 & 0.4 \\
CD11c & 1.4 & 3.9 \\
CD16 & 1.9 & 12.9 \\
CD25 & 78.6 & 68.0 \\
CD30 & 3.3 & 15.1 \\
CD34 & 0.1 & 0.5 \\
CD56 & 2.7 & 5.8 \\
CD4+CD25+ & 75.5 & 87.2 \\
\hline
\end{tabular}

* Ratio.

such as the reactivation of varicella-zoster, may promote the development of ATL in healthy HTLV-1 carriers. The progression of asymptomatic HTLV-1 infection to smoldering ATL must be considered when opportunistic infections occur in HTLV-1-positive patients. With regard to these issues, we propose two important diagnostic measures: the first involves screening blood smears for abnormal lymphocytes with bizarre, convoluted nuclei (Figures 2(a) and 2(b)) whereas the second involves monitoring serum sIL-2R levels and the percentage of CD4+CD25+ T cells over time (Table 2 ). In particular, the latter is quite a useful marker for predicting whether HTLV-1 carriers have developed immunodeficiencies, which may allow opportunistic infections or smoldering ATL to develop. Although both of our cases lacked the clinical signs of acute onset overt ATL, such as lymphadenopathy, hepatosplenomegaly, and hypercalcemia, the opportunistic infections were intractable and their outcome was rather severe because the HTLV-1 infection status was thought to be progressing significantly during the opportunistic infections.

HTLV-1-related opportunistic infections are widely recognized; indeed, CMV gastritis, gastroenterocolitis $[13,14]$, PCP [15], and disseminated herpes zoster [16] have all been reported. There have also been reports of strongyloidiasis [17], pulmonary histoplasmosis [18], and cryptococcal meningitis [19]. Here, we found that serum $\beta$-D-glucan levels in case 2 reflected PCP activity; this is consistent with the findings of previous reports $[20,21]$.

The precise mechanisms underlying the immunocompromised status in HTLV-1-infected individuals remain unknown. Yasunaga and coworkers [4] suggested that suppressed production of $\mathrm{T}$ lymphocytes in the thymus may be responsible for the immunodeficiency observed in HTLV1-infected individuals. A predominance of HTLV-1-infected CD4+ T cells is a well-recognized phenomenon in HTLV1 carriers; indeed, because HTLV-1 preferentially infects CD4+CD25+ regulatory T cells, thus, CD4+ CD25+ T cells are a major reservoir of HTLV-1 provirus $[5,22]$. This may promote inflammation and account for the pathobiology of HTLV-1 transformation and ATL development [23]. The profound immunosuppression observed in HTLV-1-infected individuals is thought to be associated with an increase in the CD4+CD25+ suppressor phenotype. These regulatory $\mathrm{T}$ cell counts were described to increase in association with susceptibility to Strongyloides hyperinfection [24]. Furthermore, Foxp3 expression by CD4+CD25+Foxp3+ regulatory $\mathrm{T}$ cells is lower in HTLV-1-infected individuals than in healthy controls $[6,7]$. In both of our patients, the regulatory CD4+CD25+ T cell subset was significantly increased when opportunistic infections occurred, although we did not examine Foxp 3 expression. In our observation, monitoring the CD4+CD25+ T cell subset over time in the occurrence of opportunistic infections seems to be a useful prognostic biomarker in HTLV-1 carriers and in smoldering ATL.

Treatment of HTLV-1-associated opportunistic infections is rather difficult due to the immunodeficient status of the patient and the infiltration of various organs by HTLV-1infected cells. Antiviral agents such as acyclovir and ganciclovir alone do not cure the disease. Aggressive chemotherapy may be required to kill HTLV-1-infected CD4+ cells, but increasing the risk of opportunistic infections and further immunosuppression. The cases described herein were not candidates for allogeneic hematopoietic stem cell transplantation (allo-HSCT) due to their age. We attempted to treat case 2 with etoposide [25]; however, its effectiveness was limited. A recent study in Japan reported that administration of the anti-CCR4 antibody, mogamulizumab, was effective and resulted in successful allo-HSCT after improvement of pulmonary function [8]. In addition, effective antiretroviral agents for HTLV-1 are essential for controlling both opportunistic infections and the neoplastic activity of ATL; however, they are not yet available. In conclusion, it is important to keep in mind that opportunistic infections can be a sign of HTLV-1 carrier or of smoldering ATL. Thus, HTLV-1 infection should be a differential diagnosis in patients with opportunistic infections such as CMV, PCP, or persistent herpes zoster and, if detected, correct staging of the ATL and appropriate management are necessary.

\section{Conflict of Interests}

The authors declare that there is no conflict of interests regarding the publication of this paper.

\section{References}

[1] K. Verdonck, E. González, S. Van Dooren, A.-M. Vandamme, G. Vanham, and E. Gotuzzo, "Human T-lymphotropic virus 1: recent knowledge about an ancient infection," The Lancet Infectious Diseases, vol. 7, no. 4, pp. 266-281, 2007. 
[2] M. D’Incan, P. Combemale, B. Verrier et al., "Transient adult T-cell leukemia/lymphoma picture during varicella infection in an HTLV-1 carrier," Leukemia, vol. 8, no. 4, pp. 682-687, 1994.

[3] P. K. C. Goon, T. Igakura, E. Hanon et al., "Human T cell lymphotropic virus type I (HTLV-I)-specific $\mathrm{CD}^{+} \mathrm{T}$ cells: immunodominance hierarchy and preferential infection with HTLV-I," Journal of Immunology, vol. 172, no. 3, pp. 1735-1743, 2004.

[4] J.-I. Yasunaga, T. Sakai, K. Nosaka et al., "Impaired production of naive $\mathrm{T}$ lymphocytes in human T-cell leukemia virus type I-infected individuals: its implications in the immunodeficient state," Blood, vol. 97, no. 10, pp. 3177-3183, 2001.

[5] Y. Yamano, N. Takenouchi, H.-C. Li et al., "Virus-induced dysfunction of $\mathrm{CD} 4^{+} \mathrm{CD} 25^{+} \mathrm{T}$ cells in patients with HTLV-Iassociated neuroimmunological disease," The Journal of Clinical Investigation, vol. 115, no. 5, pp. 1361-1368, 2005.

[6] U. Oh, C. Grant, C. Griffith, K. Fugo, N. Takenouchi, and S. Jacobson, "Reduced Foxp3 protein expression is associated with inflammatory disease during human T lymphotropic virus type 1 infection," The Journal of Infectious Diseases, vol. 193, no. 11, pp. 1557-1566, 2006.

[7] M. Abe, K. Uchihashi, T. Kazuto et al., "Foxp3 expression on normal and leukemic $\mathrm{CD} 4{ }^{+} \mathrm{CD} 25^{+} \mathrm{T}$ cells implicated in human T-cell leukemia virus type-1 is inconsistent with Treg cells," European Journal of Haematology, vol. 81, no. 3, pp. 209-217, 2008.

[8] I. Kawashima, Y. Sueki, T. Yamamoto et al., "Adult T cell leukemia-lymphoma with allo-HSCT after treatment for pulmonary involvement with Mogamulizumab," Rinshō Ketsueki, vol. 56, no. 2, pp. 210-215, 2015.

[9] M. Matsuoka, "Human T-cell leukemia virus type I (HTLVI) infection and the onset of adult T-cell leukemia (ATL)," Retrovirology, vol. 2, article 27, 2005.

[10] M. Germain, J. Williams, H. G. Skelton, and K. J. Smith, "Smoldering HTLV-1-induced T-cell lymphoma localized within the skin: a radiation-resistant tumor," International Journal of Dermatology, vol. 39, no. 11, pp. 815-821, 2000.

[11] T. Tashiro, T. Yamasaki, H. Nagai, H. Kikuchi, and M. Nasu, "Immunological studies on opportunistic infection and the development of adult T-cell leukemia," Internal Medicine, vol. 31, no. 9, pp. 1132-1136, 1992.

[12] K. Tobinai, "Current management of adult T-cell leukemia/lymphoma," Oncology, vol. 23, no. 14, pp. 1250-1256, 2009.

[13] Y. Furukawa, H. Nakamura, S. Sakamoto, and Y. Miura, "Cytomegalovirus gastritis as an initial manifestation of a patient with adult T-cell leukemia," Acta Haematologica, vol. 80, no. 4, pp. 216-218, 1988.

[14] J. Ohata, M. Matsuoka, T. Yamashita, A. Tojo, K. Tani, and S. Asano, "CD4/CD8 double-positive adult T cell leukemia with preceding cytomegaloviral gastroenterocolitis," International Journal of Hematology, vol. 69, no. 2, pp. 92-95, 1999.

[15] S. Shahnaz, D. Reich, D. Arévalo-Valencia, S. Kucinska, J. Tulczynska, and J. Fleischman, "HTLV-1-associated adult T cell leukemia lymphoma presenting as granulomatous pneumocystis jiroveci pneumonia (PJP) and hypercalcemia," Journal of General Internal Medicine, vol. 22, no. 3, pp. 420-423, 2007.

[16] N. Fujii, Y. Itoh, and H. Tomoda, "Disseminated herpes zoster with multifocal neurologic involvement in an HTLV-1 carrier," Internal Medicine, vol. 32, no. 11, pp. 854-856, 1993.
[17] O. Patey, A. Gessain, J. Breuil et al., "Seven years of recurrent severe strongyloidiasis in an HTLV-I-infected man who developed adult T-cell leukaemia," AIDS, vol. 6, no. 6, pp. 575-579, 1992.

[18] J. Kurai, T. Konishi, T. Hayabuchi, and E. Shimizu, "Case of an HTLV-1 carrier complicated with chronic pulmonary histoplasmosis," Nihon Kokyuki Gakkai Zasshi, vol. 46, no. 9, pp. 737742, 2008 (Japanese).

[19] I. Funakawa, A. Shibata, K. Mukai, A. Terao, and Y. Niki, "A case of cryptococcal meningitis in an HTLV-1 carrier," Clinical Neurology, vol. 33, no. 8, pp. 895-900, 1993.

[20] S. Teramoto, D. Sawaki, S. Okada, and Y. Ouchi, "Markedly increased plasma $(1 \rightarrow 3)-\beta$-D-glucan is a diagnostic and therapeutic indicator of Pneumocystis carinii pneumonia in a non-AIDS patient," Journal of Medical Microbiology, vol. 49, no. 4, pp. 393-394, 2000.

[21] N. Kawagishi, S. Miyagi, K. Satoh, Y. Akamatsu, S. Sekiguchi, and S. Satomi, "Usefulness of beta-D glucan in diagnosing Pneumocystis carinii pneumonia and monitoring its treatment in a living-donor liver-transplant recipient," Journal of HepatoBiliary-Pancreatic Surgery, vol. 14, no. 3, pp. 308-311, 2007.

[22] N. Araya, T. Sato, H. Ando et al., "HTLV-1 induces a Th1-like state in $\mathrm{CD} 4^{+} \mathrm{CCR} 4^{+} \mathrm{T}$ cells," Journal of Clinical Investigation, vol. 124, no. 8, pp. 3431-3442, 2014.

[23] H. P. Bal, J. Cheng, A. Murakami et al., "GITR overexpression on CD4+CD25+ HTLV-1 transformed cells: detection by massively parallel signature sequencing," Biochemical and Biophysical Research Communications, vol. 332, no. 2, pp. 569-584, 2005.

[24] M. Montes, C. Sanchez, K. Verdonck et al., "Regulatory T cell expansion in HTLV-1 and strongyloidiasis co-infection is associated with reduced IL-5 responses to Strongyloides stercoralis antigen," PLoS Neglected Tropical Diseases, vol. 3, no. 6, article e456, 2009.

[25] H. Kojima, M. Hori, A. Shibuya, T. Nagasawa, M. Miwa, and T. Abe, "Successful treatment of a patient with adult T-cell leukemia by daily oral administration of low-dose etoposide. Decrease in the amount of HTLV-I proviral DNA revealed by the polymerase chain reaction method," Cancer, vol. 72, no. 12, pp. 3614-3617, 1993. 


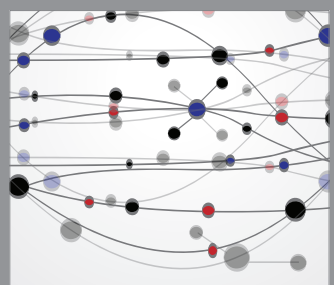

The Scientific World Journal
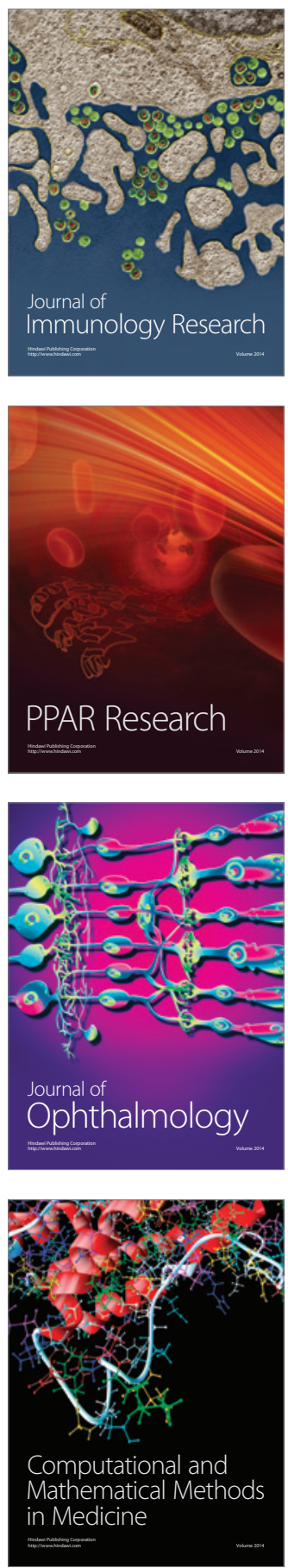

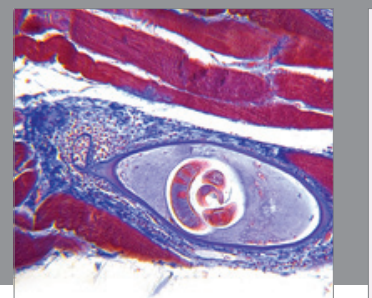

Gastroenterology

Research and Practice
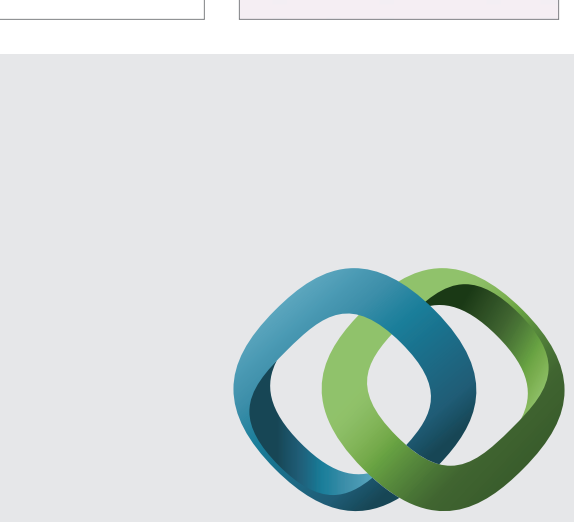

\section{Hindawi}

Submit your manuscripts at

http://www.hindawi.com
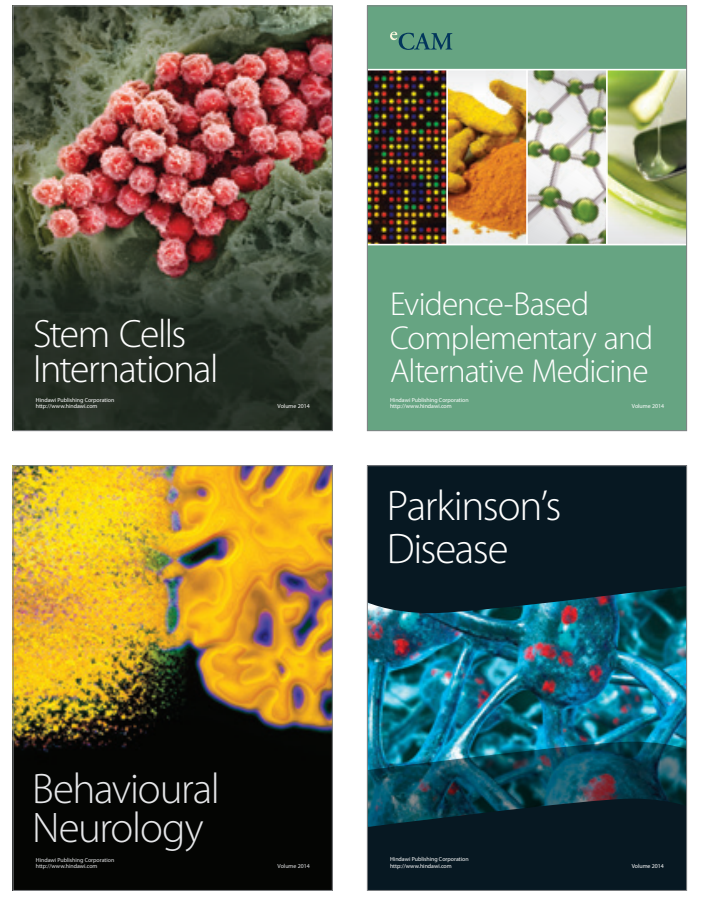
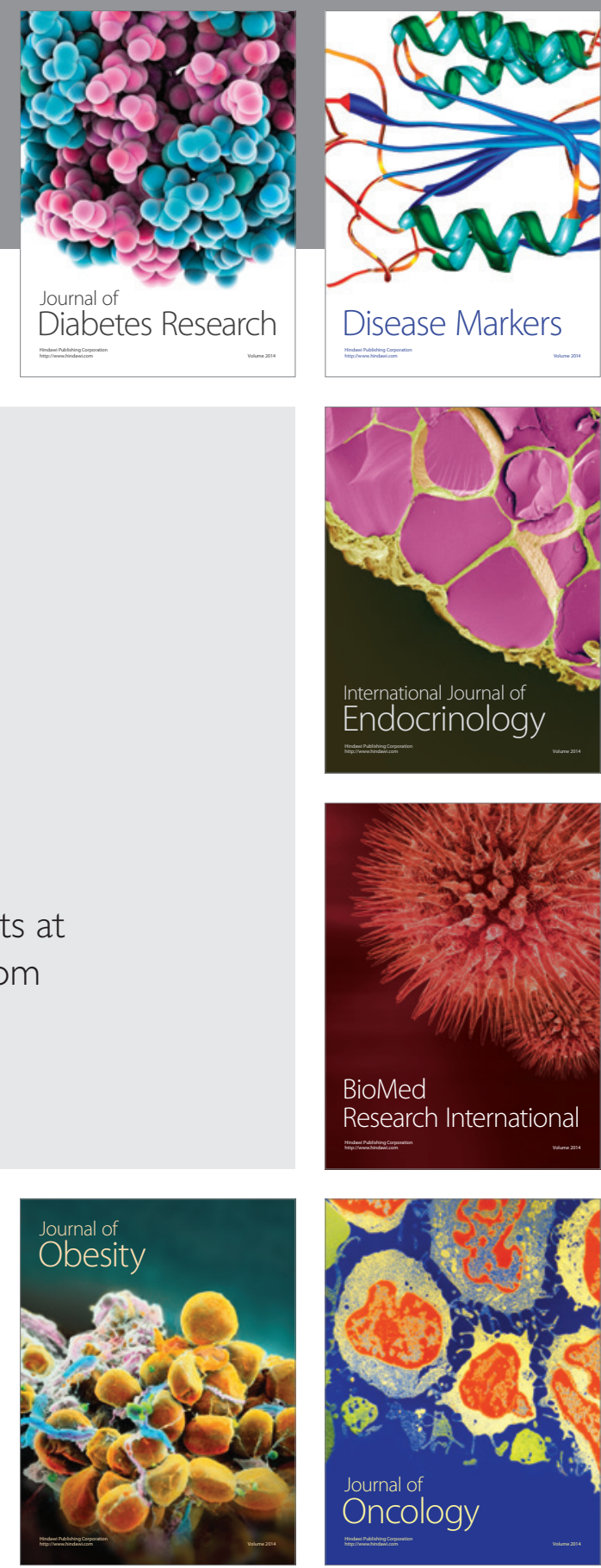

Disease Markers
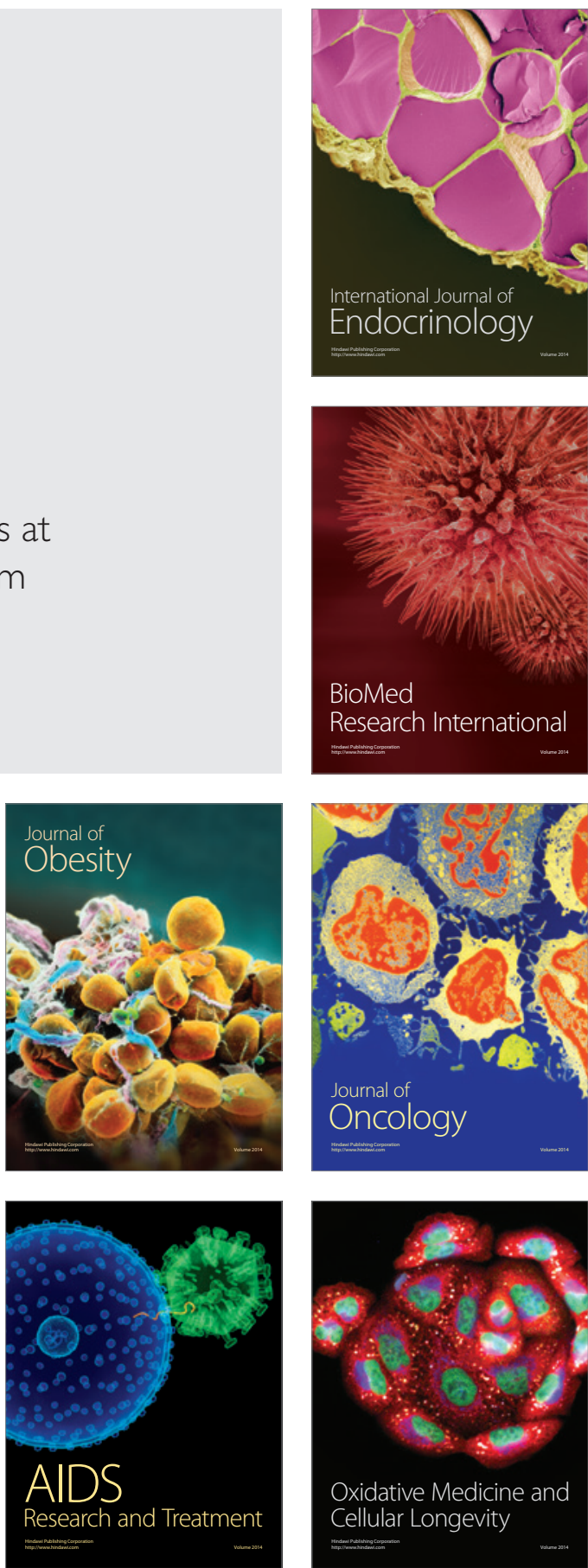